\title{
UTILIZAÇÃO DO DIAGRAMA V EM ATIVIDADES EXPERIMENTAIS DE MAGNETISMO EM SALA DE AULA DE ENSINO MÉDIO
}

\author{
RAMON TEODORO DO PRADO* \\ Instituto Federal do Espírito Santo - UFES \\ Campus de Alegre, Rod Br 482, km 47, s/n - Rive, Alegre - ES, 29520000 \\ LAÉRCIO FERRACIOLI ${ }^{\dagger}$ \\ Universidade Federal do Espírito Santo/Modelab/ \\ Mestrado Nacional Profissional em Ensino de Física-Polo 12-UFES
}

\begin{abstract}
Resumo
Este trabalho está embasado em um trabalho de mestrado (PRADO, 2015) no qual é apresentada a utilização do Diagrama V em uma atividade experimental de Magnetismo em Sala de Aula com estudantes da $3^{a}$ série do Ensino Médio de uma escola estadual pública. É descrito o Diagrama $V$ utilizado, o desenvolvimento da atividade, os resultados encontrados nas análises dos Diagramas Vs. O instrumento de Coleta de dados, Orientação e avaliação foi o Vê Epistemológico de Gowin, chamado nesse trabalho de Diagrama $V$. Os resultados revelaram que o Diagrama $V$ foi bem aceito pelos estudantes que não mostraram resistência em trabalhar com esse recurso. A abrangência teórico-metodológica do Diagrama V permitiu, também, mapear erros conceituais dos estudantes que, muitas vezes, não são devidamente observados através de instrumentos tradicionais de avaliação, tais como, provas e relatórios.
\end{abstract}

Palavras-chave: Diagrama V, Atividade Experimental e Ensino de Física.

\footnotetext{
*E-mail: ramontp05@gmail.com

†E-mail: laercio.ufes@gmail.com
} 


\begin{abstract}
This work is based on a master's (PRADO, 2015) work in which the use of V Diagram in an experimental activity of Magnetism in Classroom with students of the 3rd grade of a public state school is presented. It is described the V Diagram used, the development of the activity and the results found in the analyzes of V Diagrams. The instrument of Data collection, Guidance and evaluation was Gowin's V Epistemological, called in this work $V$ Diagram. The results revealed that the V Diagram was well accepted by students who showed no resistance in working with it. The theoretical-methodological scope of V Diagrams also allowed mapping conceptual errors of students that are often not properly observed by traditional evaluation instruments such as tests and reports.
\end{abstract}

Keywordds: V Diagram, Experimental Activity, Physics Teaching.

\title{
1 Introdução
}

O Ensino de Ciências tem sido tema de discussão por muitos especialistas da área nos últimos anos, visto que se observa um baixo rendimento por parte dos estudantes nesta área. Várias propostas têm sido apresentadas no intuito de buscar um melhor aproveitamento no Ensino de Ciências, sejam novos métodos de ensino, a utilização do computador com simulações, aulas com encenações teatrais e a realização de atividade experimental. Dentro deste contexto, o uso do laboratório de ciências e a atividade experimental aparecem como alternativa na tentativa melhorar o desempenho e o interesse dos estudantes pela Ciência.

A maior parte das escolas públicas do Brasil, não possuem laboratórios de Ciências, sendo este um entrave para as aulas experimentais nas escolas. Assim, materiais para a atividade experimental tornam-se mais difíceis ainda. Desta forma, buscam-se alternativas para a realização de atividades experimentais com os estudantes de ensino médio na disciplina de Física. Muitas atividades experimentais são realizadas em sala de aula e/ou em espaços alternativos das escolas como o pátio e a quadra de esportes. Os materiais para a realização da atividade experimental são providenciados pelos próprios estudantes, visto que as escolas também não possuem recursos para aquisição dos mesmos.

Segundo o Globo Educação (RIBEIRO,2013), "apenas 10,6\% das escolas brasileiras, entre públicas e privadas, possuíam laboratórios de Ciências em 2012, segundo o INEP, órgão do Ministério da Educação". Dentre as escolas que tinham espaço, 60,1\% eram públicas e 39,9\% eram privadas. Ainda de acordo com o Globo Educação estudos internacionais mostram que laboratórios de Ciências fazem diferença no desempenho dos estudantes. Escolas que têm laboratórios afirmam que percebem um maior interesse dos alunos quando a aula é prática.

Dentro deste contexto, onde a $89,4 \%$ das escolas brasileiras não possuem laboratório de ciências, encontra-se a escola onde foi realizado este estudo. Assim nosso estudo foi realizado dentro de sala de aula, onde os próprios alunos providenciaram todo o material necessário para a realização da atividade 
experimental, as ferramentas nas quais tiveram que trabalhar e as mesas de estudo tornaram-se bancadas para montagem e estudo da atividade experimental, é o experimento para além do laboratório.

Outro ponto importante em aulas experimentais é de se propor uma orientação adequada aos estudantes do que realmente fazer em uma atividade experimental ou o que, como e para quê realizar a atividade. Observa-se que muitos estudantes realizam a atividade sem ter a menor ideia do que está acontecendo e $o$ porquê de ele estar realizando aquela tarefa, o que torna a aula totalmente desinteressante para o estudante fazendo com que esta não atinja o objetivo desejado. Nesta linha, buscou-se uma ferramenta que viesse nortear os estudantes em atividades experimentais, sendo esta, o Vê Epistemológico de Gowin (1981), ferramenta criada por R.D. Gowin como forma de "desempacotar" o conhecimento.

Nesse contexto, este estudo foi desenvolvido com o objetivo geral de investigar a utilização do Diagrama $\mathrm{V}$ como instrumento de orientação, coleta de dados e avaliação em atividades experimentais realizadas em sala de aula na disciplina de Física para estudantes de Ensino Médio visando promover o entendimento da articulação entre teoria e prática.

\section{Referencial Teórico}

Estudos apontam para o estímulo e melhoria de estudantes de ciências quando estes trabalham com atividades experimentais (BORGES,2002; RIBEIRO,2013). A atividade experimental costuma colaborar na melhoria do desempenho acadêmico dos estudantes desde que seja bem planejada e com objetivos bem determinados de forma que a atividade não fique entediante para os estudantes e que o fenômeno físico a ser estudado seja realmente entendido. Segundo Borges (2002):

As principais críticas que se fazem a estas atividades práticas é que elas não são efetivamente relacionadas aos conceitos físicos; que muitas delas não são relevantes do ponto de vista dos estudantes, já que tanto o problema como o procedimento para resolvê-lo estão previamente determinados; que as operações de montagem dos equipamentos, as atividades de coleta de dados e os cálculos para obter respostas esperadas consomem muito ou todo o tempo disponível. Com isso, os estudantes dedicam pouco tempo à análise e interpretação dos resultados e do próprio significado da atividade realizada. (BORGES,2002, p. 296)

Nesse contexto, este trabalho relata uma proposta de trabalhar a atividade experimental com o auxílio do Diagrama $\mathrm{V}$ como instrumento de orientação, coleta de dados e avaliação de atividades experimentais realizada em sala de aula.

\subsection{O Diagrama V}

Este texto apresenta a ideia desenvolvida por D.B. Gowin (1981) e utilizada por Ferracioli (2005) para análise da produção do conhecimento. A partir dessa perspectiva, Gowin (1981) denominou-o de Vê Epistemológico de Gowin ou simplesmente Vê de Gowin que no nosso trabalho será chamado de Diagrama V. A ideia foi construir um instrumento para análise da produção de conhecimento ou para 'desempacotar' documentos em artigos de pesquisa (GOWIN, 1981;2005). Baseado nessa visão o autor propõe cinco questões para a produção do conhecimento: 
1. Quais são as Questões-Focos?

2. Quais são os Conceitos-Chaves?

3. Quais são os Métodos para responder à Questão-Foco?

4. Quais as Asserções de Conhecimento?

5. Quais as Asserções de valor?

Neste contexto, a Questão-Foco determina o objetivo específico do trabalho a ser estudado, direciona o estudo, e é a pergunta que informa sobre o ponto central de um estudo ou de uma pesquisa, ela diz, de fato, o que será estudado, pesquisado.

Os Conceitos-Chave são os conceitos envolvidos na Questão-Foco e na pesquisa como um todo, relativo(s) à(s) área(s) de conhecimento, abrangida(s) na investigação. Esses conceitos devem estar ligados de modo a formar uma Estrutura Conceitual. Os Métodos são os procedimentos adotados para se chegar à resposta da questão foco. Métodos incluem o planejamento das etapas da investigação, equipamentos, instrumentos e técnicas para a coleta de dados e o processo de análise.

Através dos métodos/transformações chega-se à resposta da Questão-Foco, que são as Asserções de Conhecimento as quais se constituem na resposta à questão foco ou ao resultado do estudo.

Uma vez obtidas as asserções de conhecimento, questiona-se a sua significância, utilidade e importância, obtendo-se, assim, as Asserções de Valor.

Assim, o processo de investigação é visto através da contínua interação dessas questões. A QuestãoFoco delimita e norteia o que será pesquisado; os Conceitos-Chaves proveem a sustentação teórica para o questionamento proposto pela questão-foco; os Métodos determinam o desenvolver da pesquisa que gera as respostas à questão-foco que são as Asserções de Conhecimento, às quais, analisadas à luz de sua relevância, produzem as Asserções de Valor.

Para uma melhor visualização desse procedimento e detalhamento da interação das cinco questões, Gowin (1981) propõe uma representação gráfica denominada por ele de 'V' Epistemológico e que mais tarde passou a ser conhecido como ' $V$ ' de Gowin ou simplesmente Diagrama V. A Figura 01 apresenta o Diagrama $\mathrm{V}$ conforme a forma concebida pelo autor do mesmo.

No lado esquerdo do ' $\mathrm{V}$ ' encontra-se o domínio conceitual que representa o pensar da pesquisa, enquanto que no lado direito encontra-se o domínio metodológico representando o fazer da pesquisa. A questão foco encontra-se no centro, pois suas respostas são obtidas a partir de uma contínua interação entre os dois lados do ' $\mathrm{V}$ '. Na base do ' $\mathrm{V}$ ' encontram-se os eventos que ocorrem naturalmente ou que são feitos acontecer e que, de modo geral, representam a origem da produção do conhecimento.

O Diagrama V pode ser utilizado iniciando-se por qualquer um dos lados uma vez que o conhecimento é gerado a partir da contínua interação entre esses dois domínios.

Ao iniciar pelo lado conceitual ou do pensar a investigação, que representa a postura filosófica e teórica que o investigador se baseia para observar o evento em estudo, ficará assentado o embasamento teórico para o desenvolvimento da pesquisa como um todo. 


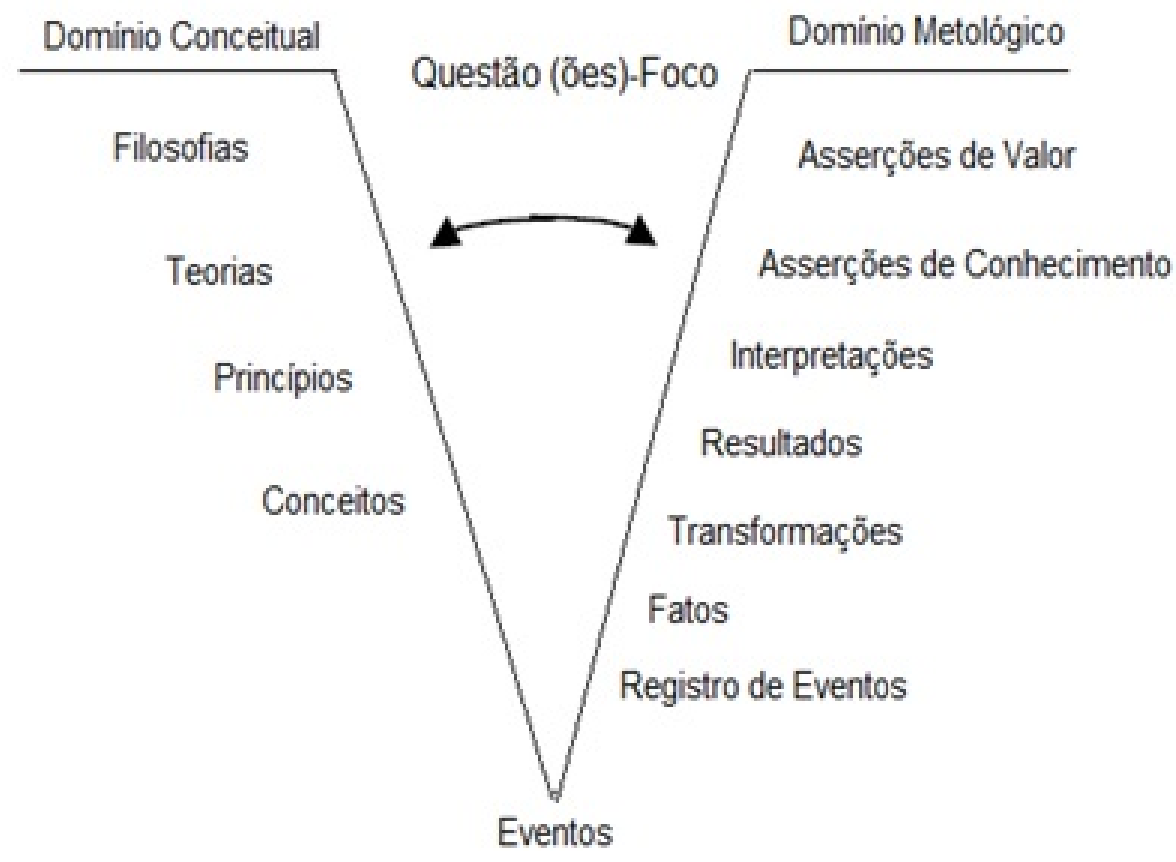

Figura 1: O Diagrama V de acordo com Gowin (1981).

O caminhar por este lado do Pensar nos leva ao evento a ser observado, localizado na base do ' $\mathrm{V}$ '. A partir daí entramos pelo lado metodológico ou do fazer a investigação. A contínua interação desses dois lados nos leva as respostas da pesquisa com o consequente julgamento de sua relevância e utilidade.

Dessa forma, as cinco questões e o Diagrama V constituem-se no procedimento proposto por Gowin (1981), que pode ser utilizado como estratégia para o ensino experimental.

\subsection{Diagrama V Utilizado na Atividade Experimental}

Para a utilização do Diagrama V no contexto do Ensino Médio fez-se necessário adaptá-lo para a realidade dos estudantes, uma vez que desconhecem tanto a terminologia quanto a estrutura pensar-fazer proposta por Gowin (1981). Dessa forma, para a realização deste estudo, foi feita uma adaptação do Diagrama V apresentado na Figura 1.

A principal adaptação foi em relação ao item Evento que foi ampliado em três caixas, a saber: Montagem, $O$ que foi feito e $O$ que foi encontrado. O objetivo é levar o estudante a explicitar o passo a passo do experimento realizado em sala de aula e proporcionar uma análise qualitativa. Dessa forma, as caixas tiveram os objetivos:

- Montagem: solicitar que os estudantes construíssem o circuito.

- O que foi feito: levar o estudante descrever os procedimentos realizados para responder à QuestãoFoco. 
- O que foi encontrado: levar o estudante a descrever o observado a partir da caixa $O$ que foi feito para explicitar o resultado encontrado na manipulação do circuito.

Outra adaptação foi a exploração da previsão do comportamento esperado pelo estudante antes da realização do experimento e a verificação do comportamento descrito após a sua realização (BATISTTELA, 2007). Essa adaptação foi traduzida com a inclusão de duas novas caixas com os objetivos:

- O que você espera como resultado desse experimento? levantamento do conhecimento prévio (NOVAK \& GOWIN, 1984 dos estudantes sobre o evento antes da realização do experimento;

- O resultado encontrado coincide com o que você esperava? levar o estudante a explicitar se o comportamento esperado foi verificado, explicando as possíveis diferenças e através de levantamento de hipóteses para justificá-las.

A caixa Conclusões e Justificativas representa a articulação dos itens Resultados, Interpretação e Asserções de Conhecimento na busca de uma linguagem adequada aos estudantes de Ensino Médio. Assim como a caixa Registros/Dados representa a articulação dos itens Registros do Evento e Fatos.

O item Teoria foi fornecido previamente pelo professor aos alunos visando levar os grupos a se concentrarem nos demais itens do Diagrama V. A Questão-Foco foi de inteira responsabilidade dos grupos, tendo o professor orientado para que fosse preenchido de forma atrelada diretamente ao objetivo da atividade experimental.

\section{Metodologia}

\subsection{Contexto do Estudo}

Seguindo a tendência nacional, a escola onde foi realizado esse estudo não possui laboratório de Física e, por esse motivo, as atividades experimentais foram desenvolvidas em sala de aula. A escola onde se realizou o presente estudo, no ano de 2014, foi até contemplada com um espaço para que fosse utilizado como laboratório de Física e Matemática. No entanto, os materiais que chegaram para trabalhar com atividades experimentais, não contemplam todos os estudantes, ou seja, o material que foi enviado para a escola, apresenta um total de cinco kits para trabalhar todo o conteúdo de Física do Ensino Médio.

Desta forma, se usássemos o material disponibilizado, a atividade experimental seria apenas demonstrativa, sem que os estudantes interagissem diretamente com o fenômeno. Desta forma foi pedido para que os estudantes providenciassem todo o material para a realização da atividade experimental. Portanto, embora a escola tenha um espaço para que no futuro seja um laboratório, as atividades são e foram realizadas em sala de aula.

\subsection{Os Experimentos do Estudo: bússola, visualização das linhas de indução e eletroímã}

No terceiro trimestre letivo do ano de 2014 foi proposta aos estudantes a realização de três experimentos envolvendo conceitos de Magnetismo, sendo estes: A construção de uma bússola, a visualização das linhas 


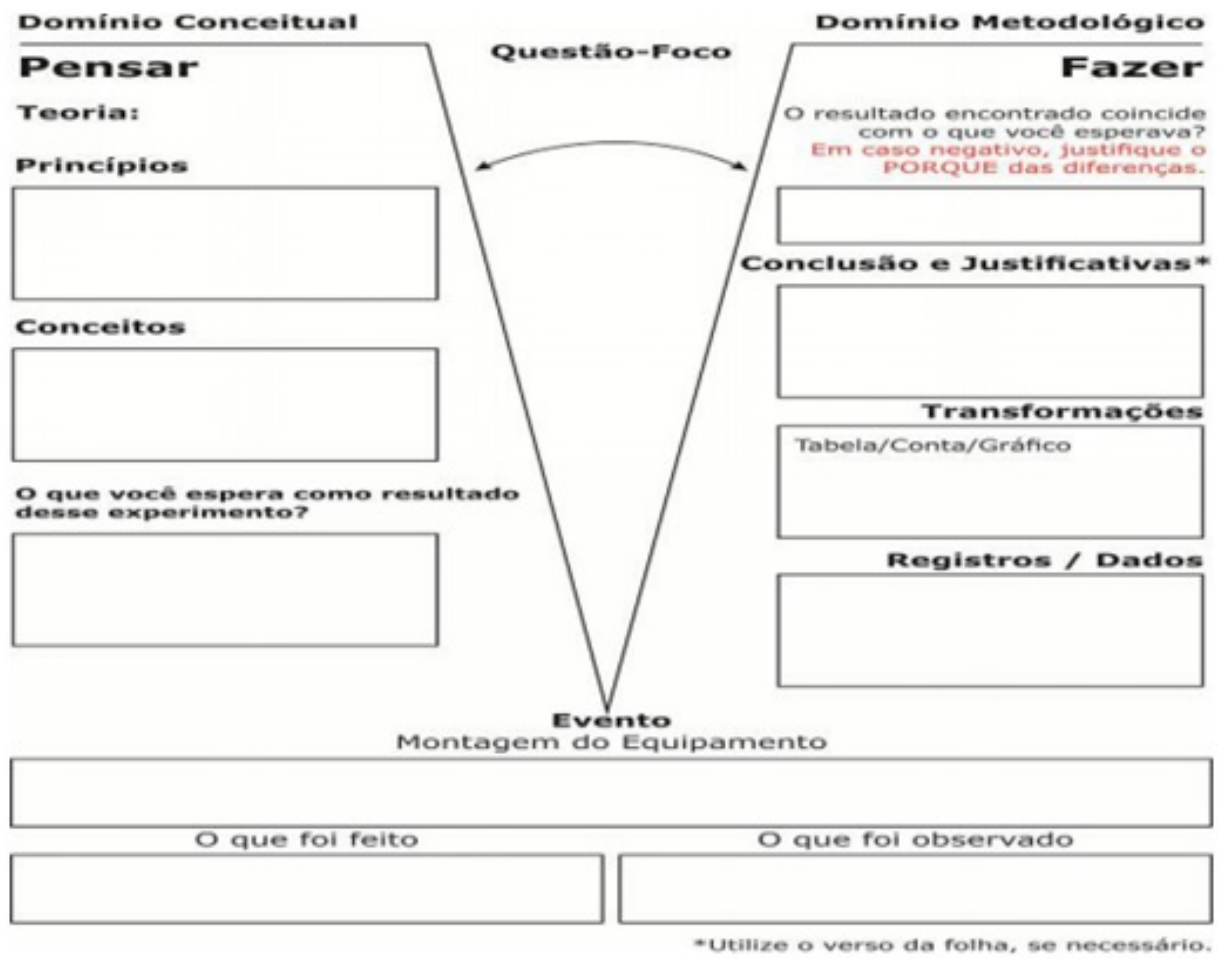

Figura 2: O Diagrama V adaptado para a realização do presente estudo.

de Indução Magnética no óleo vegetal com auxílio de limalhas de aço e a construção de um Eletroímã. Antes da realização dessas atividades foram ministradas aulas teóricas sobre todo o assunto de Magnetismo, partindo dos conceitos iniciais e chegando até a Lei de Indução de Faraday.

\subsection{Os Sujeitos da Pesquisa}

O estudo foi realizado na EEEFM Clovis Borges Miguel, Serra-ES. Os sujeitos foram estudantes da $3^{\text {a }}$ Série do Ensino Médio do turno matutino, em sua grande maioria, adolescentes na faixa dos 17 anos de idade. O estudo foi realizado em uma turma com 32 estudantes divididos em grupos de 3 e 4 integrantes.

\subsection{O Instrumento de Coleta de Dados}

O Diagrama V da Figura 2 foi utilizado como guia de orientação para a realização do experimento e instrumento de avaliação dos alunos. Os grupos foram solicitados a preencher o Diagrama V ao longo de três momentos conforme descrito na Tabela 1. O conjunto dos diagramas preenchidos pelos estudantes foi a base de dados do estudo. 
Revista do Professor de Física • Brasília, vol. 1, n. 1 • 2017

Tabela 1: Planejamento da Atividade Experimental com o Diagrama V

\begin{tabular}{|c|c|c|}
\hline $\mathbf{1}^{\mathbf{a}}$ Aula & Objetivo & Construir os experimentos disponibilizados pelo professor. \\
\hline & Duração & Hora/Aula: 55 minutos \\
\hline & Formato & Aula Prática. \\
\hline & Descrição & Os estudantes começaram a montagem dos experimentos. \\
\hline $\mathbf{2}^{\mathbf{a}}$ Aula & Objetivo & Orientar os estudantes na montagem dos experimentos. \\
\hline & Duração & Hora/Aula: 55 minutos \\
\hline & Formato & Aula expositiva e prática \\
\hline & Descrição & $\begin{array}{r}\text { Os grupos foram orientados sobre a montagem dos experimentos. } \\
\text { Preenchimento do Lado Conceitual do Diagrama V. }\end{array}$ \\
\hline $\mathbf{3}^{\mathbf{a}}$ Aula & Objetivo & Realizar o experimento com o circuito montado \\
\hline & Duração & Hora/Aula: 55 minutos \\
\hline & Formato & Aula prática \\
\hline & Descrição & $\begin{array}{r}\text { Os grupos terminaram a montagem dos seus experimentos e } \\
\text { finalizaram o preenchimento do Diagrama V. }\end{array}$ \\
\hline
\end{tabular}

\subsection{Descrição do Estudo}

A atividade experimental foi realizada ao longo de três aulas de 55 minutos cada. Os estudantes receberam o roteiro do experimento uma semana antes de sua realização para que providenciassem todo o material necessário. A Tabela 1 apresenta o planejamento do estudo.

\section{Análise e Discussão dos Dados}

Para análise de dados foram utilizados os Diagramas Vs produzidos pelos estudantes, sendo feita a leitura e a análise de cata item do Diagrama V. Nessa atividade experimental, 7 (sete) estudantes produziram 3 Diagramas Vs, 1 (um) para cada experimento, sendo que a decisão de produzir os três Diagramas Vs partiu dos próprios estudantes. Os outros 25 estudantes produziram apenas uma versão para a atividade experimental de Magnetismo como um todo.

Como foram realizados três experimentos nessa atividade, mesmo os estudantes que produziram 1 (um) Diagrama V, escreveram, em sua maioria três Questões-foco, sendo 1 (uma) para cada experimento, como era esperado. Alguns estudantes escreveram apenas 1 ou 2 Questões-foco não contemplando toda a atividade experimental. Mesmo os estudantes sendo orientados a escrever a Questão-foco antes da realização da atividade, alguns escreveram sua questão após sua realização, tendo alguns fenômenos chamados a atenção dos estudantes neste momento.

Para essa atividade experimental, todas as questões elaboradas pelos estudantes atenderam à expectativa esperada, mesmo com alguns estudantes elaborando apenas uma Questão-foco. Um Diagrama V chamou a atenção por ter questões enxutas, porém, contemplando toda a atividade experimental tendo sido consideradas bem elaboradas como podemos observar abaixo. 
- "Ao magnetizar uma agulha, ela toma uma orientação?";

- "A palha de aço, dentro do óleo, segue as linhas de indução ao esfregar o ímã no frasco?";

- "Ligando os extremos do fio dos terminais da pilha, o prego se magnetiza?"

Podemos observar que o estudante usa Conceitos pertinentes à atividade experimental, menciona o que será o Evento e elabora uma questão para cada experimento, buscando atender a toda a atividade experimental.

Os estudantes que construíram três Diagramas Vs, apresentaram resultados mais robustos e completos para todos os itens do Diagrama V. Na Questão-foco chegaram a elaborar três perguntas para um único experimento, como podemos observar no exemplar abaixo do estudante A 18.

- "O que acontece quando um eletroímã é ligado a uma pilha? O que ocorre se o prego é tirado? O que ocorre quando ambas as situações são desligadas da pilha?"

- "A bússola criada segue a orientação do campo magnético terrestre? O que acontece quando um ímã é aproximado dela?";

- "Como fica o pó da palha de aço dentro do frasco? O que ocorre quando ímãs são aproximados? Como são as linhas de indução e o campo magnético no interior do frasco?"

Esse estudante (A 18), ao elaborar mais de uma Questão-foco para um mesmo experimento, acabou explorando mais cada atividade do que os estudantes que elaboraram apenas uma Questão-foco. Podemos observar que o estudante usa conceitos pertinentes indicando de forma bem clara o que seria o Evento em cada caso.

O Domínio Conceitual ficou preenchido com vários conceitos pertencentes aos experimentos com um maior destaque para: Ímãs, Linhas de Indução, Magnetismo e Imantação, não aparecendo nenhum conceito que não fizesse parte dos conteúdos abordados nos experimentos. Nos Princípios a maior parte dos registros consistiu em: Campo Magnético, Lei da indução de Faraday, Efeito Joule e Lei da atração e repulsão dos polos magnéticos.

No quesito $O$ que você espera como resultado desse experimento? encontramos respostas diretas à Questão-foco, expectativas em relação aos experimentos de forma geral, descrição do que seria o objetivo da atividade experimental e respostas com suas possíveis justificativas baseadas na teoria estudada até aquele momento.

Para o grupo de estudantes que construiu apenas um Diagrama V, a descrição do Evento ficou sucinta, ou seja, como havia pouco espaço para descrição da atividade realizada, os estudantes escreveram de forma resumida não deixando claro o que foi feito para responder à Questão-foco. Ainda para o mesmo grupo, alguns estudantes acabaram descrevendo apenas uma das atividades experimentais, deixando de mencionar as outras duas atividades.

No entanto, alguns estudantes conseguiram organizar o seu Diagrama $\mathrm{V}$, numerando cada atividade experimental, descrevendo o material utilizado em cada atividade, o que foi feito e o que foi observado de forma objetiva e sequencial descrevendo exatamente o que foi realizado na atividade. Abaixo descrevemos o que foi descrito pelo estudante A 27. 
- Montagem do Equipamento:

- “Exp. 1: Foi utilizado uma agulha, pedaço de ímã, copo com água, pedaço de papel toalha”;

- “Exp. 2: Foi utilizado pedaço de palha de aço, 2 ímãs, frasco de óleo mineral, funil”;

- “Exp. 3: Foi utilizado um prego, fio de cobre, pilha de 1,5 V, clipes, alicate e fita isolante”.

- O que foi feito:

- “Exp. 1: Foi posicionado a agulha magnetizada por cima do papel dentro do copo com água”;

- “Exp. 2: Foi colocado pó da palha de aço dentro do frasco agitado e passado ímã na lateral de cada lado do frasco";

- "Exp.3: Foi enrolado fio no prego, fixado sua pontas em cada polo da pilha e aproximado clipes nas extremidades do prego”.

- O que foi Observado:

- "Exp. 1: A agulha tomou uma orientação seguindo as orientações dos ponteiros de uma bússola”;

- “Exp. 2: Gerou um campo magnético e deu para verificar as linhas de indução”;

- “Exp. 3: O prego se magnetizou e atraiu os clipes”.

Como podemos observar, esse estudante também escreveu o Evento de forma bem resumida, porém deixou claro o que foi feito nas três atividades e de uma forma na qual foi possível verificar a causa e consequência de cada um das atividades.

O outro grupo de 7 estudantes que construíram 3 Diagramas Vs, ou seja, 1 (um) para cada atividade, conseguiu deixar bem claro o que foi feito em cada atividade experimental, pois tinham mais espaço no Evento, o que permitiu que escrevessem detalhadamente todo o procedimento experimental, desde a montagem do equipamento até as "perturbações/alterações" que realizaram nos experimentos com o intuito de responder à Questão-foco. O quesito no qual houve uma diferença significativa foi justamente no Evento, pois construindo um Diagrama V para cada atividade experimental, possibilitou aos estudantes fazer uma descrição mais completa de todo o procedimento experimental.

Os Registros e as Transformações tiveram o pior desempenho nessa atividade experimental, com boa parte dos estudantes simplesmente não registrando nada nos dois quesitos. De um total de 32 Diagramas Vs, em apenas 14 encontramos esses dois quesitos preenchidos. O que pode ter contribuído para um baixo desempenho foi o fato de no Diagrama V que foi entregue aos estudantes e no material explicando o Diagrama V, era feita uma descrição que informava que as Transformações poderiam ser apresentadas na forma de um gráfico, uma tabela, estatísticas, correlações ou categorizações que poderiam ser feitas a partir dos Registros. Como a atividade de Magnetismo foi apenas fenomenológica, não tendo valores de grandezas físicas envolvidas, os estudantes não tinham como montar tabelas, gráficos ou verificar contas de fórmulas, não conseguindo assim fazer nenhum registro nesses dois quesitos. 
Revista do Professor de Física • Brasília, vol. 1, n. 1 • 2017

Tabela 2: "Tabela” construída pela estudante A 18 descrevendo as Transformações.

\begin{tabular}{|c|c|c|}
\hline \multicolumn{3}{|c|}{ Transformações do Prego } \\
\hline Situação & Acontecimento & Motivo \\
\hline $\begin{array}{c}\text { Prego antes de } \\
\text { começar a experiência }\end{array}$ & $\begin{array}{l}\text { Não atrai } \\
\text { os clipes }\end{array}$ & $\begin{array}{l}\text { O prego é apenas um ferro } \\
\text { que não está imantado }\end{array}$ \\
\hline $\begin{array}{l}\text { Prego dentro da bobina } \\
\text { com apenas um polo } \\
\text { conectado a pilha }\end{array}$ & $\begin{array}{l}\text { Não atrai } \\
\text { os clipes }\end{array}$ & $\begin{array}{c}\text { Com apenas um dos polos conectados, } \\
\text { não há passagem de corrente e } \\
\text { como consequência não há campo magnético e } \\
\text { não ocorre imantação }\end{array}$ \\
\hline $\begin{array}{l}\text { Prego dentro da bobina } \\
\text { com os dois polos } \\
\text { conectados à pilha. }\end{array}$ & $\begin{array}{c}\text { Atrai } \\
\text { os clipes }\end{array}$ & $\begin{array}{l}\text { Ao conectar as extremidades aos dois polos da pilha, } \\
\text { começa a ter passagem de corrente elétrica e } \\
\text { passa a atuar o campo magnético e } \\
\text { com isso o prego no interior da bobina é imantado }\end{array}$ \\
\hline $\begin{array}{l}\text { Prego dentro da bobina } \\
\text { com apenas um dos polos } \\
\text { conectados a pilha }\end{array}$ & $\begin{array}{l}\text { Não atrai } \\
\text { os clipes }\end{array}$ & $\begin{array}{l}\text { Ao desconectar uma das extremidades } \\
\text { do polo da pilha, a corrente } \\
\text { e o campo magnético param de atuar } \\
\text { e o prego perde a imantação } \\
\text { retornando ao seu estado normal }\end{array}$ \\
\hline
\end{tabular}

Nos 14 (catorze) Diagramas Vs que apresentaram os dois quesitos, foram descritos o que acontecia em cada experimento, desenhos dos fenômenos, material utilizado e resultados fenomenológicos de cada atividade experimental. Mesmo sendo registrado algo nesses quesitos, podemos observar que nem todos podem ser considerados, de fato, como Registros e Transformações.

Dos 7 (sete) estudantes que construíram 3 Diagramas Vs, 3 (três) estudantes registraram informações nesses quesitos, principalmente nos Registros em que anotaram o resultado fenomenológico da atividade experimental. Uma estudante conseguiu fazer a Transformação descrevendo, em um quadro, a situação inicial de cada experimento e "o que ocorreu", nomenclatura criada pela própria estudante, nessa situação inicial e na situação posterior. Em um dos experimentos essa estudante descreveu a Situação, o Acontecimento e o Motivo que ocasionou esse acontecimento como podemos perceber no exemplar mostrado na Tabela 2.

Como podemos observar, a estudante conseguiu descrever o experimento e os resultados obtidos em cada etapa da atividade experimental, justificando o "porquê" de cada fenômeno observado. Foi a melhor forma de organizar as Transformações apresentada por todos os estudantes nessa atividade experimental.

As Conclusões \& Justificativas apresentaram muitas respostas diretas às Questões-foco e em alguns casos sem justificativas, ou seja, os alunos afirmaram que a atividade atendeu suas expectativas e foi realizada com sucesso. Abaixo descrevemos algumas respostas:

- Aluno A17: “Que uma agulha magnetizada sobre o papel e sobre a água ela irá apontar para o norte";

- Aluno A8: "1) Ele é atraído como se fosse um ímã. 2) A pilha se esquenta porque passa uma 
corrente elétrica nela”;

- Aluno A33: “Concluo que o experimento foi realizado com sucesso, obtendo tudo que se era esperado”.

Podemos observar nas três respostas acima que os alunos não conseguiram descrever de forma clara suas conclusões, não justificando suas respostas ou deixando vaga a conclusão. Esse foi o caso do aluno A33, que, além de não termos uma resposta à Questão-foco, não menciona o que foi obtido na atividade experimental, não situando o leitor sobre os fenômenos observados. Como podemos observar ainda, nem todas questões elaboradas pelos próprios estudantes foram respondidas. Acima foram descritas as conclusões inteiras encontradas nos Diagramas Vs desses estudantes.

Por outro lado, alguns estudantes conseguiram descrever de forma bem objetiva e com justificativas coerentes suas conclusões. Abaixo descrevemos algumas respostas:

- Aluno A2: “A agulha se orienta aproximadamente na direção norte-sul geográfica. Isso significa que existe um campo magnético terrestre criado pela Terra. É o campo magnético terrestre”;

- Aluno A 27: Exp.1 “A agulha magnetizada toma orientação, pois existe um campo magnético”. Exp. 2 "O ímã origina um campo magnético seguindo as linhas de indução”. Exp.3 "O campo magnético estabelecido no interior da pilha orienta os ímãs elementares do prego magnetizando-o, ele passa a atrair os clipes";

- Aluno A 30: "Quando aproximamos o ímã da agulha ela para de seguir o campo magnético terrestre e passou a seguir o campo do ímã”.

Os três exemplares de respostas anteriores se mostram coerentes com a atividade experimental realizada. A resposta do aluno A 2 apresenta uma resposta com uma justificativa. No entanto, esse aluno apresenta a conclusão apenas para uma das atividades realizadas, deixando de mencionar o que foi realizado nas outras duas atividades experimentais. A resposta do aluno A 27 apresenta três conclusões, ou seja, 1 (uma) para cada atividade. Apesar de respostas curtas, elas apresentaram conceitos envolvidos nos experimentos, justificativas para cada fenômeno observado e uma resposta direta à Questão-foco. O terceiro exemplar é de um dos estudantes que apresentaram três Diagramas Vs. A conclusão mencionada é para o experimento da bússola que eles construíram e está relacionada diretamente à sua Questão-foco, utiliza conceitos e justificativa para alteração da posição da agulha ao aproximar um outro ímã perto da bússola.

De uma forma geral, as Conclusões \& Justificativas dos estudantes que apresentaram três Diagramas Vs ficaram mais completas, justamente por ter mais espaço e pensarem em cada experimento de forma separadamente, construindo, assim, respostas mais robustas e coerentes com a própria Questão-foco elaborada para cada experimento.

\section{Considerações Finais}

Esse trabalho relatou a utilização do Diagrama V em atividades experimentais de Magnetismo em Sala de Aula de Ensino Médio em uma turma da $3^{\text {a }}$ série de uma escola estadual pública da cidade de Serra, região Metropolitana da Grande Vitória, no Estado do Espírito Santo. 
Foi realizada uma atividade experimental sobre Magnetismo envolvendo três experimentos: A construção de uma bússola, de um Eletroímã e a visualização das linhas de Indução Magnética. Ao todo, foram necessárias três aulas de 55 minutos para o início e término das atividades. Toda a atividade foi realizada em sala de aula com os estudantes providenciando todo o material necessário para a realização dos experimentos.

Foi a terceira vez que os estudantes trabalharam com atividade experimental tendo o Diagrama V como instrumento de coleta de dados e orientação. Nesse mesmo ano letivo, já havia sido trabalhado outras duas atividades experimentais usando-se o Diagrama V, o que permitiu aos estudantes concentrarem suas atenções exclusivamente na realização do experimento.

A elaboração da Questão-foco antes da realização da atividade, fez com que os estudantes pensassem sobre o experimento antes de sua execução. Muitos estudantes encontraram dificuldade para a elaboração da questão-foco, pois não estão acostumados a fazerem esse tipo de tarefa nas atividades experimentais. Alguns, inclusive, elaboraram uma questão ou ainda acrescentaram outras questões no seu Diagrama V durante a realização da atividade. O fato de os estudantes pensarem em uma pergunta para investigar foi uma grande contribuição que o Diagrama V forneceu, visto que, na maioria dos casos, os alunos partem para a realização do experimento, coleta de dados e os cálculos, quando necessário, sem ter ideia do objetivo principal ou qualquer outro objetivo que ele pretenda atingir ao executar tal atividade.

O Diagrama $V$ foi útil também como instrumento de coleta de dados, pois possibilitou uma organização na realização da atividade mostrando aos estudantes o passo a passo de cada etapa da atividade experimental não deixando assim que ficassem desorientados durante o decorrer da atividade.

Fazendo a leitura de cada componente do Diagrama V foi possível mapear erros conceituais cometidos pelos estudantes que muitas vezes não são identificados em relatórios tradicionais. Foi possível verificar, por exemplo, que alguns estudantes ainda confundem Conceitos com Leis \& Princípios fazendo inversão no momento dos registros destes, mesmo já tendo sido trabalhado o conteúdo teórico em sala de aula.

Finalizando, o Diagrama V foi eficaz como instrumento de Coleta de Dados, Orientação e Avaliação em atividades experimentais de Física em Sala de Aula, mostrando ser útil como instrumento norteador dessas atividades dando um maior significado para os estudantes.

\section{Agradecimentos}

Trabalho parcialmente financiado pelo CNPq \& CAPES, FACITEC e FAPES.

\section{Referências}

[1] BATISTELLA, C.A.R. Atividades de Ótica Exploradas no Ensino Médio através de Reflexões Epistemológicas com o Emprego do V de Gowin. Dissertação (mestrado em Ensino de Física Programa de Pós-Graduação em Ensino de Física- Instituto de Física- UFRGS), Porto Alegre, 2007.

[2] BORGES, A. T. Novos rumos para o laboratório escolar de ciências. Caderno Brasileiro de Ensino de Física 19(3), 291-313, 2002. 
[3] FERRACIOLI, L. O V epistemológico como Instrumento Metodológico para o processo de Investigação. Revista Didática Sistêmica, Fundação Universidade Federal do Rio Grande, 2005.

[4] FERRACIOLI, L. O Diagrama V no Ensino Experimental. Publicação Interna do ModeLab. Departamento de Física, Universidade Federal do Espírito Santo, 2014.

[5] GOWIN, D.B. Educating. Ithaca, Cornel University Press, 1981.

[6] GOWIN, D.B.; ALVAREZ, M.C. The Art Educating with V Diagrams. Cambridge University Press, New York, 2005.

[7] NOVAK, J.D. and GOWIN, D. B. Learning How To Learn. New York: Cambridge University Press. 1994.

[8] PRADO, Ramon Teodoro do. A Utilização do Diagrama V em Atividades Experimentais de Física em Sala de Aula de Ensino Médio. 2015. Dissertação de Mestrado - Centro de Ciências Exatas, Universidade Federal do Espírito Santo, Vitória, 2015.

[9] RIBEIRO, M. Só 11\% das Escolas Brasileiras têm Laboratórios de Ciências: O Globo Educação. Disponível em:<http://oglobo.globo.com/educacao/so-11-das-escolas-brasileiras-tem-laboratoriode-ciencias-10804574\#ixzz210LZgz4m>. Acesso em 04/12/2013. 